\title{
Ycs4 subunit of Saccharomyces cerevisiae condensin binds DNA and modulates the enzyme turnover
}

\author{
Rupa Sarkar ${ }^{1}$, Zoya M. Petrushenko1, Dean S. Dawson² and Valentin V. Rybenkov ${ }^{1 *}$ \\ 1Department of Chemistry and Biochemistry, University of Oklahoma, 101 Stephenson Parkway, \\ Norman, OK 73019, USA \\ ${ }^{2}$ Oklahoma Medical Research Foundation, 825 N.E. 13th Street, Oklahoma City, OK 73104, \\ USA
}




\section{Supplemental Figures}

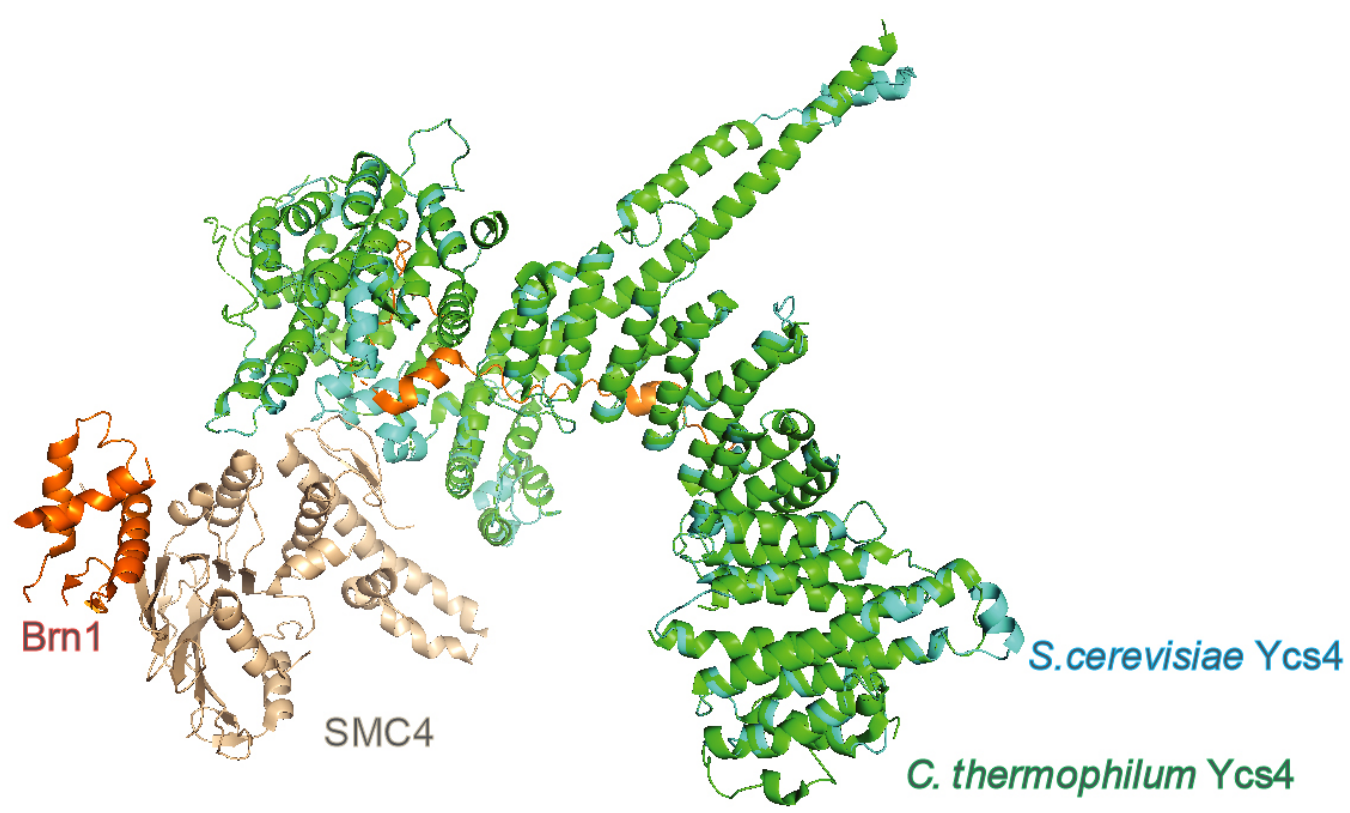

Figure S1. Alignment of the C. thermophilum Ycs4-Brn1-SMC4 (6QJ4) with the homology modeled S. cerevisiae Ycs4.

A
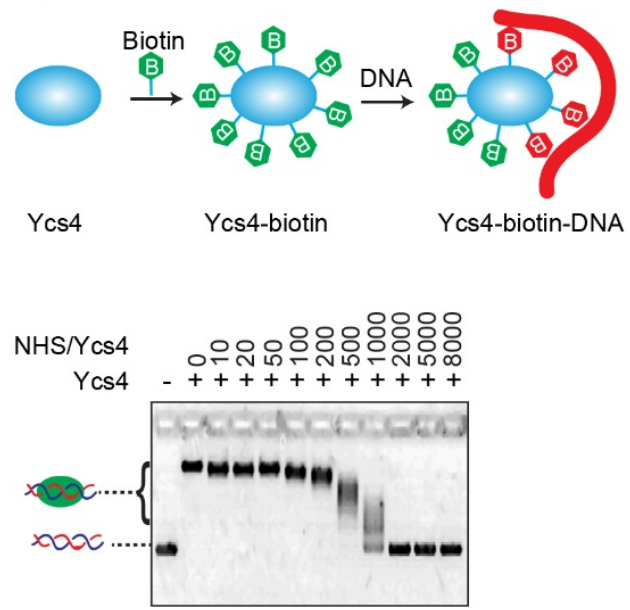

B

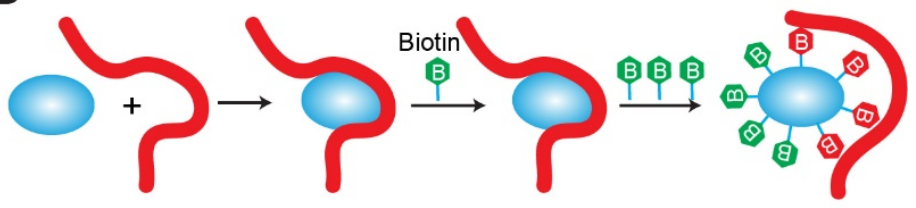

Ycs4

DNA

Ycs4-DNA

Ycs4-biotin-DNA

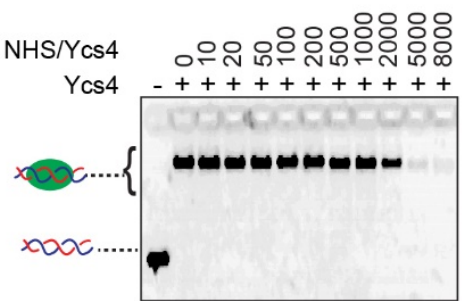

Figure S2. Effect of biotin labeling on DNA binding by Ycs4. $12 \mu \mathrm{M}$ of Ycs4 was incubated with $100 \mathrm{pmol}$ of $900 \mathrm{bp}$ DNA for $30 \mathrm{~min}$ at $30^{\circ} \mathrm{C}$ before (A) or after (B) Ycs4 was biotinylated in the presence of the indicated molar excess of sulfo NHS-biotin (NHS) and the protein-DNA complex formation assessed using gel electrophoresis. 


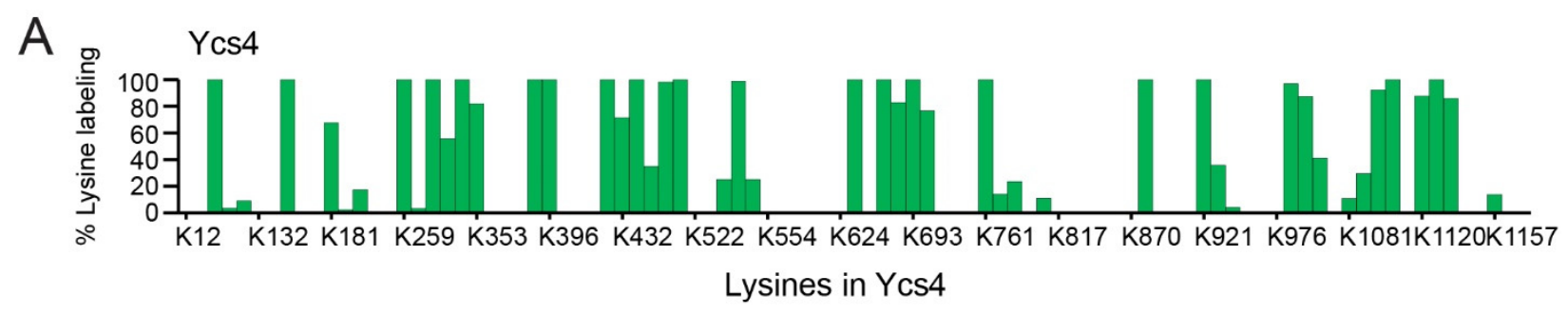

B

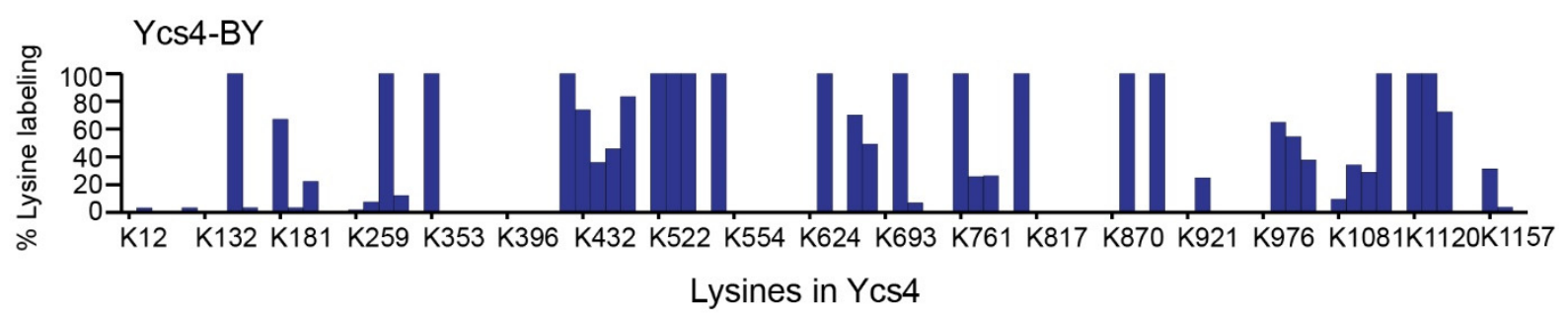

C

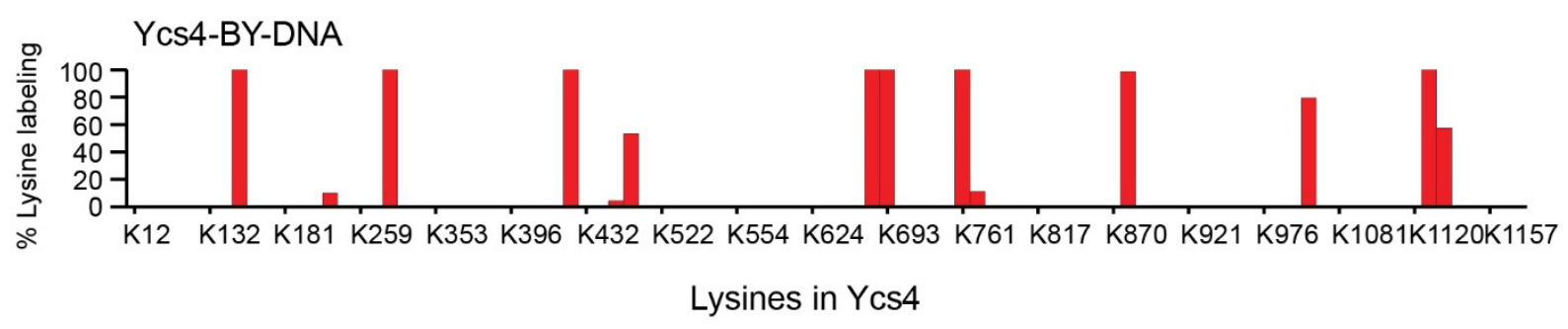

Figure S3. Biotin labeling efficiency of Ycs4 in (A) Ycs4 alone, (B) Ycs4-Brn1-Ycg1 (Ycs4-BY) complex, and (C) Ycs4-BY-DNA complex.

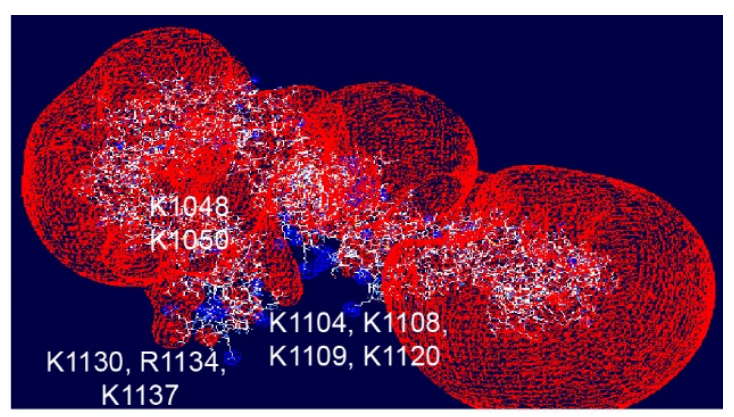

Figure S4. Electrostatic potential mapping detects positively charged patches at the C-terminus end of Ycs4 while the major part of the protein is negatively charged. 


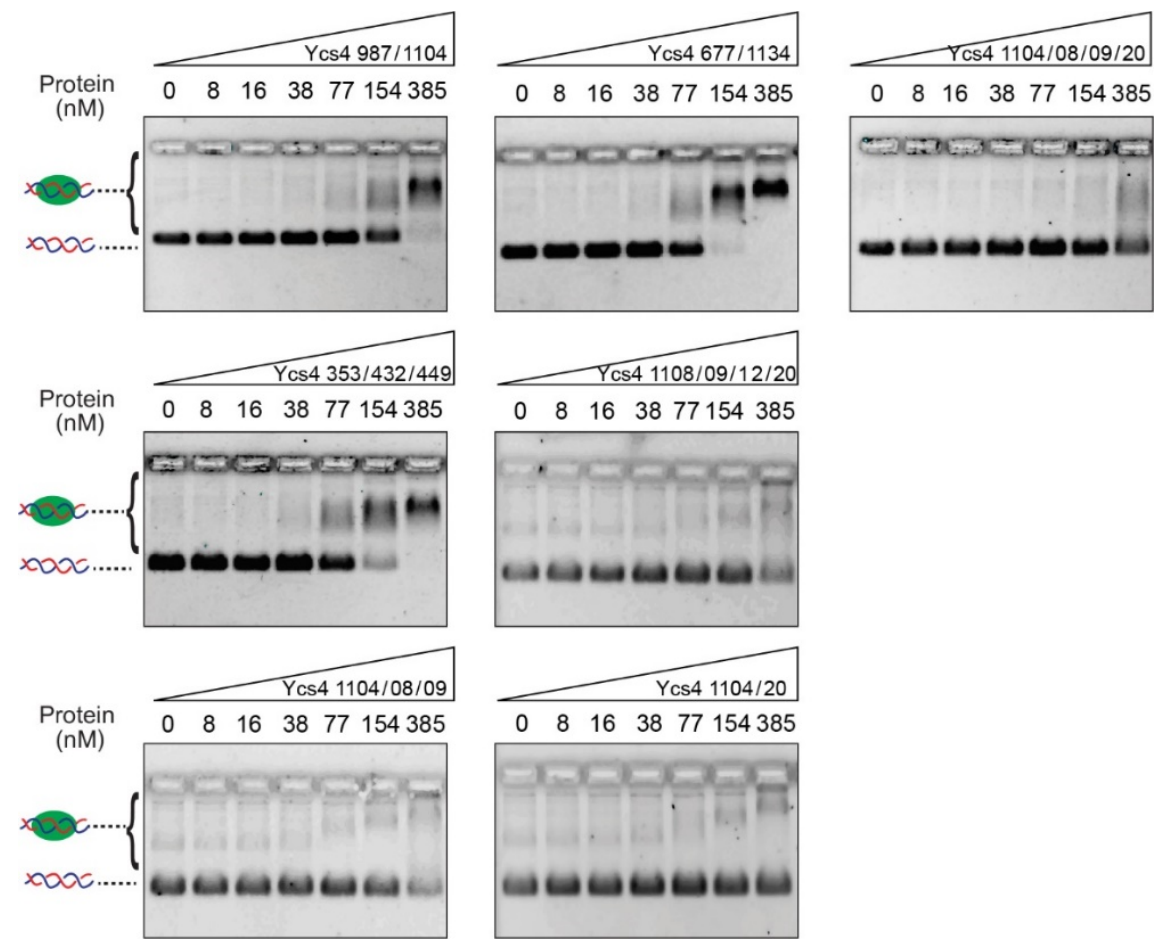

Figure S5. Gel shift assay of the mutant Ycs4 proteins.

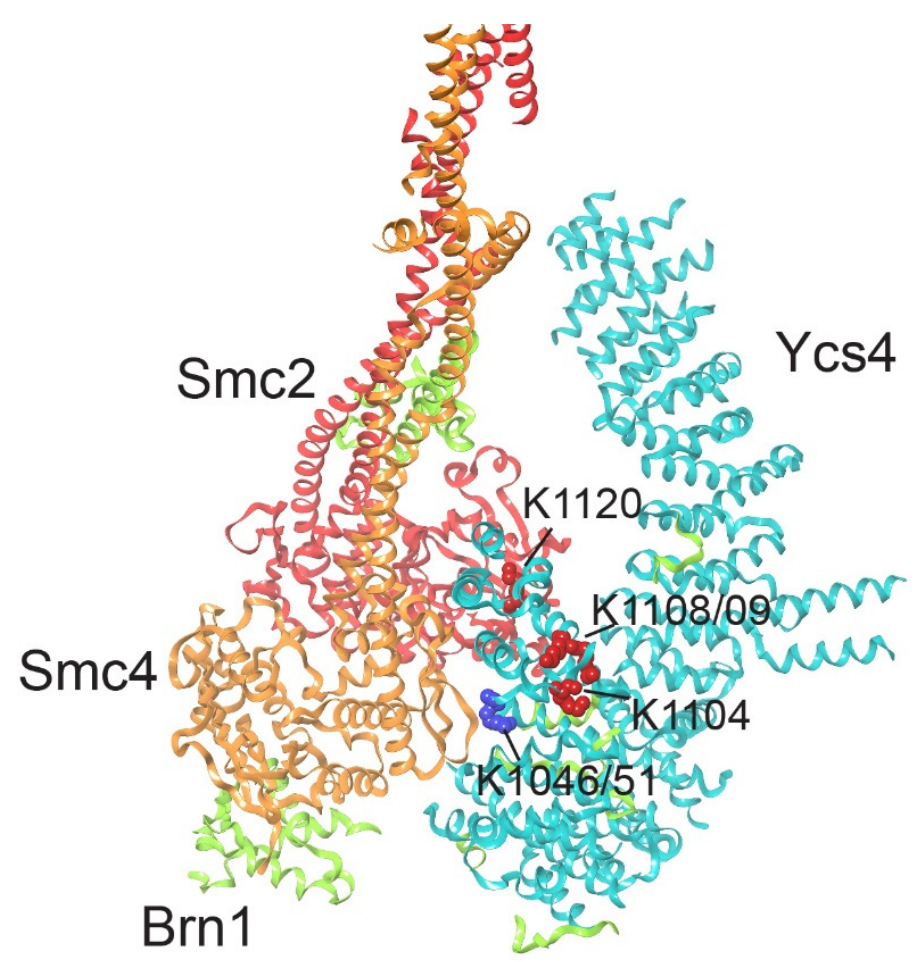

Figure S6. DNA binding lysines of Ycs4 (red) mapped onto the cryo-EM structure of the protein (PDB: 6YVU). Residues 1047-1050 were not shown in the structure; instead, the flanking residues 1046 and 1051 are highlighted (blue). 


\section{Supplemental Tables}

Table S1. Biotinylation levels (\%) of lysines in Ycs4 alone, Ycs4-Brn1-Ycg1 complex (Ycs4-BY) and Ycs4-BY-DNA complex (YBY-DNA). -, peptide not detected.

\begin{tabular}{|c|c|c|c|c|c|c|c|c|c|}
\hline \multirow{2}{*}{$\begin{array}{l}\text { Ycs4 } \\
\text { Lysines }\end{array}$} & \multicolumn{3}{|c|}{ Complex } & \multirow{2}{*}{$\begin{array}{c}\text { Ycg1 } \\
\text { Lysines }\end{array}$} & \multicolumn{2}{|c|}{ Complex } & \multirow{2}{*}{$\begin{array}{c}\text { Brn1 } \\
\text { Lysines }\end{array}$} & \multicolumn{2}{|c|}{ Complex } \\
\hline & Ycs 4 & $\begin{array}{c}\text { Ycs4- } \\
\text { BY }\end{array}$ & $\begin{array}{l}\text { YBY- } \\
\text { DNA }\end{array}$ & & $\begin{array}{c}\text { Ycs4- } \\
\text { BY }\end{array}$ & $\begin{array}{l}\text { YBY- } \\
\text { DNA }\end{array}$ & & $\begin{array}{l}\text { Ycs4- } \\
\text { BY }\end{array}$ & $\begin{array}{l}\text { YBY- } \\
\text { DNA }\end{array}$ \\
\hline $\mathrm{K} 12$ & 0.0 & - & 0.0 & K12 & 0.0 & 0.0 & K36 & 14.1 & 0.0 \\
\hline K68 & 0.0 & 3.1 & 0.0 & K23 & 0.0 & 0.0 & K42 & 56.5 & 100.0 \\
\hline K86 & 100.0 & - & - & K33 & 100.0 & 100.0 & K64 & 0.0 & 0.0 \\
\hline K89 & 3.5 & - & - & K39 & 12.7 & 0.0 & K74 & - & 0.0 \\
\hline K109 & 8.9 & 3.2 & 0.0 & K40 & 100.0 & - & K84 & - & - \\
\hline K132 & 0.0 & 0.0 & 0.0 & K44 & 21.2 & - & K99 & 89.9 & 0.0 \\
\hline K145 & - & - & - & K60 & 98.5 & - & K108 & - & - \\
\hline K148 & 100.0 & 100.0 & 100.0 & K64 & 100.0 & 100.0 & K174 & 14.3 & 0.0 \\
\hline K158 & 0.0 & 3.3 & 0.0 & K69 & 20.4 & 0.0 & K176 & 74.6 & - \\
\hline K173 & 0.0 & 0.0 & 0.0 & K70 & 98.7 & 99.6 & K189 & 4.8 & 0.0 \\
\hline K181 & 67.6 & 67.0 & 0.0 & K80 & - & - & K190 & 100.0 & 0.0 \\
\hline K189 & 2.2 & 3.3 & 0.0 & K97 & 58.6 & 100.0 & K201 & 0.0 & 0.0 \\
\hline K211 & 17.3 & 22.4 & 0.0 & K98 & 0.0 & 0.0 & K223 & 31.1 & 5.0 \\
\hline K216 & 0.0 & 0.0 & - & K102 & - & - & K232 & 100.0 & 87.9 \\
\hline K228 & - & - & - & K131 & 100.0 & 97.8 & K236 & 100.0 & 1.3 \\
\hline K259 & 100.0 & 1.8 & 0.0 & K165 & 82.3 & - & K289 & 0.0 & 0.0 \\
\hline K276 & 3.4 & 7.3 & 0.0 & K184 & - & - & K316 & 43.4 & 0.0 \\
\hline K286 & 100.0 & 100.0 & 100.0 & K261 & 100.0 & 100.0 & K388 & - & - \\
\hline K292 & 55.8 & 12.2 & 0.0 & K266 & - & - & K409 & - & - \\
\hline K300 & 100.0 & - & - & K296 & - & - & K414 & - & - \\
\hline K353 & 82.0 & 100.0 & 0.0 & K317 & 4.3 & 0.0 & K415 & - & - \\
\hline K377 & - & - & - & K328 & - & - & K421 & 100.0 & 100.0 \\
\hline K384 & - & - & - & K344 & 39.8 & 0.0 & K439 & - & 3.7 \\
\hline K391 & - & - & - & K346 & 35.7 & 11.5 & K445 & 100.0 & 16.3 \\
\hline K394 & 100.0 & - & - & K352 & 4.4 & 0.0 & $\mathrm{~K} 450$ & 100.0 & 76.2 \\
\hline K396 & 100.0 & - & - & K387 & 0.0 & 0.0 & K451 & 68.3 & 56.4 \\
\hline K398 & 0.0 & - & - & K462 & 0.0 & 0.0 & K452 & 87.9 & 56.8 \\
\hline K420 & - & - & - & K469 & - & - & K454 & 46.8 & 0.0 \\
\hline K424 & - & - & - & K476 & 90.8 & 0.0 & K456 & 35.5 & - \\
\hline K428 & 100.0 & 100.0 & 100.0 & K496 & - & 0.0 & K457 & 100.0 & 0.0 \\
\hline K432 & 71.5 & 73.9 & 0.0 & K502 & 100.0 & 47.2 & K465 & 0.0 & 0.0 \\
\hline K449 & 100.0 & 36.0 & 0.0 & K504 & 100.0 & 29.6 & K473 & 100.0 & 0.0 \\
\hline K460 & 35.0 & 45.9 & 4.2 & K506 & 100.0 & 0.0 & K478 & 100.0 & 100.0 \\
\hline K461 & 98.4 & 83.3 & 53.3 & K507 & 100.0 & - & K482 & 100.0 & 88.6 \\
\hline K498 & 100.0 & - & 0.0 & K568 & 0.0 & 0.0 & K488 & 83.5 & 96.0 \\
\hline K522 & - & 100.0 & 0.0 & K624 & 100.0 & - & K491 & - & - \\
\hline K524 & - & 100.0 & - & K635 & - & - & K515 & 87.3 & 5.9 \\
\hline K531 & 25.0 & 100.0 & - & K650 & 100.0 & - & K519 & 11.3 & 0.0 \\
\hline
\end{tabular}




\begin{tabular}{|c|c|c|c|c|c|c|c|c|c|}
\hline K538 & 98.9 & 0.0 & 0.0 & K656 & 0.0 & - & K527 & - & - \\
\hline K542 & 25.0 & 100.0 & - & K680 & 95.8 & 0.0 & K540 & 29.3 & 0.0 \\
\hline K554 & 0.5 & - & - & K688 & 0.0 & 0.0 & K568 & 100.0 & 18.6 \\
\hline K582 & - & - & - & K692 & - & - & K573 & 0.0 & 100.0 \\
\hline K583 & - & - & - & K695 & - & - & K575 & - & 0.0 \\
\hline K591 & - & - & - & K712 & - & - & K579 & - & - \\
\hline K609 & - & - & - & K798 & 44.1 & - & K618 & 89.4 & 0.0 \\
\hline K624 & - & - & - & K823 & 97.8 & 51.4 & K628 & 32.1 & 2.6 \\
\hline K630 & 100.0 & 100.0 & - & K824 & 37.7 & 0.0 & K635 & - & - \\
\hline K658 & - & - & - & K837 & 0.0 & 0.0 & K643 & 100.0 & 100.0 \\
\hline K677 & 100.0 & 70.2 & - & K844 & 59.0 & 2.6 & K644 & 100.0 & 100.0 \\
\hline K682 & 82.8 & 49.3 & 100.0 & K845 & 0.0 & 0.0 & K651 & - & 100.0 \\
\hline K693 & 100.0 & - & 100.0 & K848 & - & - & K652 & - & 100.0 \\
\hline K697 & 76.6 & 100.0 & 0.0 & K849 & - & - & K669 & - & - \\
\hline K720 & 0.0 & 6.7 & 0.0 & K870 & 6.9 & 0.0 & K688 & - & 94.1 \\
\hline K736 & 0.0 & 0.0 & 0.0 & K890 & 0.0 & 0.0 & K691 & 100.0 & 0.0 \\
\hline K754 & - & - & - & K895 & 100.0 & 100.0 & K701 & 6.6 & 0.0 \\
\hline K761 & 100.0 & 100.0 & 100.0 & K916 & - & - & K709 & 100.0 & 0.0 \\
\hline K773 & 14.0 & 25.7 & 11.2 & K936 & 100.0 & - & & & \\
\hline K774 & 23.3 & 26.3 & 0.0 & K958 & 4.6 & 0.0 & & & \\
\hline K784 & 0.0 & - & - & K977 & - & - & & & \\
\hline K805 & 11.0 & 100.0 & 0.0 & K990 & 83.2 & 9.7 & & & \\
\hline K817 & - & - & - & K1005 & 0.0 & 0.0 & & & \\
\hline K824 & - & - & - & K1015 & 0.0 & - & & & \\
\hline K856 & 0.3 & 0.0 & 0.0 & K1026 & 0.0 & 0.0 & & & \\
\hline K863 & 0.0 & 0.0 & 0.0 & & & & & & \\
\hline K869 & - & - & - & & & & & & \\
\hline K870 & - & - & - & & & & & & \\
\hline K872 & 100.0 & 100.0 & 98.7 & & & & & & \\
\hline K881 & - & - & - & & & & & & \\
\hline K883 & 0.0 & 100.0 & 0.0 & & & & & & \\
\hline K900 & 0.0 & 0.0 & 0.0 & & & & & & \\
\hline K921 & 100.0 & - & 0.0 & & & & & & \\
\hline K930 & 35.7 & 25.0 & 0.3 & & & & & & \\
\hline K935 & 4.2 & 0.0 & 0.0 & & & & & & \\
\hline K965 & - & - & - & & & & & & \\
\hline K972 & - & - & - & & & & & & \\
\hline K976 & - & - & - & & & & & & \\
\hline K987 & 96.9 & 64.9 & 0.0 & & & & & & \\
\hline K1048 & 87.3 & 54.5 & 0.0 & & & & & & \\
\hline K1050 & 41.2 & 37.7 & 79.4 & & & & & & \\
\hline K1058 & 0.0 & 0.0 & 0.0 & & & & & & \\
\hline K1081 & 10.8 & 9.4 & 0.0 & & & & & & \\
\hline K1104 & 29.5 & 34.1 & 0.0 & & & & & & \\
\hline K1108 & 92.3 & 29.1 & - & & & & & & \\
\hline
\end{tabular}




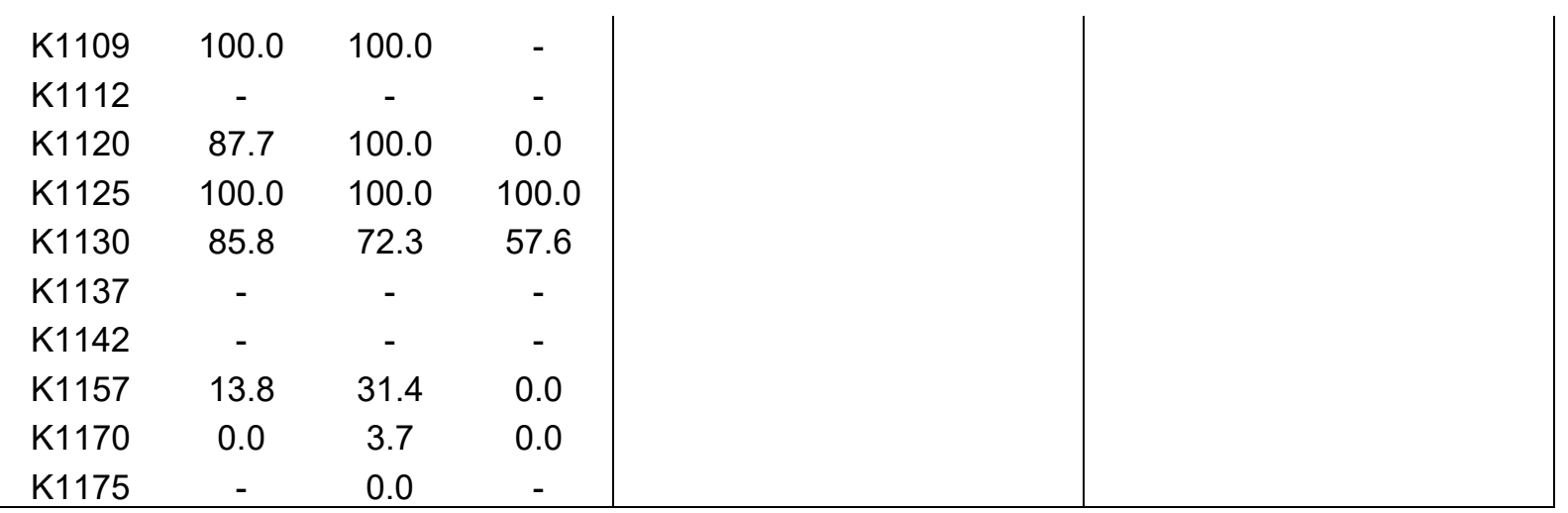

